\title{
Las objeciones de Gassendi a las Meditaciones METAFÍSICAS DE DESCARTES EN SU CONTEXTO FILOSÓFICO ${ }^{1}$
}

\author{
Samuel Herrera-Balboa ${ }^{2}$
}

\begin{abstract}
Resumen: En general la disputa entre Gassendi y Descartes ha sido tratada desde el punto de vista cartesiano y, en ese contexto, nuestro artículo se centra en la filosofía de Gassendi. Buscamos un modo para entender la lógica o la estrategia de las objeciones gassendianas, tratando de mostrar los supuestos filosóficos que operan bajo las críticas a Descartes. Junto con ello, mostraremos parte de la recepción contemporánea de la polémica y explicaremos los tópicos más problemáticos adoptados por Gassendi relativos al método y las asunciones relativas a la sustancia. Para cumplir estos objetivos, estudiaremos las objeciones de Gassendi a Descartes en las Quintas Objeciones a las Meditaciones Metafísicas y, también, en la Disquisitio metaphysica seu dubitationes et instantiae adversus Renati Cartesii metaphysicam et responsa, obra publicada por Gassendi en 1644.
\end{abstract}

Palabras claves: Gassendi. Objeciones. Descartes. Escepticismo. Sustancia.

\section{INTRODUCCIÓN}

El intercambio epistolar entre Pierre Gassendi (1592-1655) y René Descartes (1596-1650), dos figuras de marca mayor en la modernidad temprana, ocultó una disputa filosófica capital porque importantes temáticas quedaron encubiertas por los aspectos polémicos. Los diversos problemas tratados en la disputa -tales como la naturaleza de la sustancia y del mundo, la fuente del conocimiento, el alcance de las facultades del intelecto y su acceso a

\footnotetext{
${ }^{1}$ Se agradece al proyecto Fondecyt de Iniciación No11140387 "Filosofia natural de Pierre Gassendi: fundamentos, límites y horizontes para comprender las objeciones gassendistas a la filosofía cartesiana”. Además, este artículo fue financiado parcialmente por la Universidad de La Frontera, proyecto DI190111. Agradezco las observaciones realizadas por el profesor Dr. Leonel Toledo (UACM-México).

2 Profesor del Área de Investigación Filosófica, Departamento de Ciencias Sociales, Universidad de La Frontera Temuco - Chile, Temuco, Chile. (D) https://orcid.org/0000-0002-0509-2907 Email: samuel.herrera@ufrontera.cl
}

http://doi.org/10.1590/0101-3173.2020.v43n3.28.p369

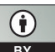

This is an open-access article distributed under the terms of the Creative Commons Attribution License. 
la verdad, la validez del método y los criterios epistémicos- dieron vida al siglo XVII y continuaron durante el siglo XVIII.

A partir de lo anterior, este artículo retoma la controversia entre ambos filósofos con la finalidad de comprender las objeciones de Gassendi a las Meditaciones metafísicas ${ }^{3}$. Esta perspectiva pretende ampliar las interpretaciones hasta ahora realizadas porque regularmente la disputa ha sido entendida desde el juicio cartesiano. Mientras la filosofía cartesiana ha sido ampliamente difundida, la filosofía que inspiró las quintas objeciones ha quedado situada en una suerte de penumbra ${ }^{4}$.

Nuestro objetivo es intentar comprender la naturaleza de la crítica realizada por Gassendi a Descartes a través de la presentación de algunos casos que dejan entrever un modo de enfrentamiento muy sui generis. La hipótesis que guía este trabajo es que podemos explicar la crítica gassendiana solo si entendemos que en ella se hace uso de una actitud y de estrategias escépticas metódicas que son yuxtapuestas con el neo-epicureísmo y, que todo ello, tuvo como objetivo contraponerse a los argumentos de la filosofía cartesiana y no plantear un sistema filosófico. Si los ejemplos críticos propuestos por Gassendi pueden clarificar la estrategia para enfrentar al texto cartesiano, entonces, podremos sostener con plausibilidad que Gassendi entendió correctamente algunos aspectos de la filosofía de Descartes y solo desde una comprensión tal, la propia crítica de Gassendi se ve iluminada. Para sustentar esta posición intentaremos centrarnos, primero, en la recepción contemporánea de la controversia para luego mostrar la forma escéptica en que funciona el análisis de Gassendi; luego, mostraremos las objeciones específicas respecto del método y, finalmente, daremos cuenta de la crítica gassendiana relativa al conocimiento de la sustancia sostenida por Descartes.

\section{LA RECEPCIÓN CONTEMPORÁNEA DE LA CONTROVERSIA}

Recordemos que la disputa generada por los dos filósofos franceses del siglo XVII, ocurrió públicamente entre los años 1641 y 1647 . Este periodo

\footnotetext{
${ }^{3}$ Quisiera mencionar que al citar el texto de las Meditaciones en español, nos hemos remitido a la traducción de Vidal Peña. Esta decisión es muy importante para dialogar con el texto y, muy especialmente, para tomar en cuenta algunas de las notas explicativas que propone el traductor y que son parte importante del trasfondo que intenta mostrar mi posición acerca de las críticas ofrecidas por Gassendi.

${ }^{4}$ En parte, esto es una situación interpretativa comprensible porque la tarea exegética del pensamiento de Gassendi está lejos de ser completada por los estudios contemporáneos.
} 
se inicia con el intercambio epistolar respecto de las Meditaciones metafisicas y su posterior publicación en el libro donde se integraron las Respuestas de Descartes a las Quintas objeciones realizadas por Gassendi. Como es bien sabido, Descartes dio instrucciones a Clerselier de no traducir las objeciones de Gassendi al francés. Pese a esta indicación, Clerselier incluye su traducción de las Quintas objeciones en la edición de 1647 y hoy las encontramos publicadas en la versión latina bajo la edición de Adam y Tannery5. La versión francesa de las Quintas objeciones la encontramos en la edición del corpus cartesiano llevada a cabo por Ferdinand Alquié (DESCARTES, 1988), y en español, las encontramos en la traducción de Vidal Peña (DESCARTES, 1988).

La discusión tuvo su extensión en la respuesta de Gassendi (1962) con la publicación de su obra Disquisitio metaphysica seu dubitationes et instantiae adversus Renati Cartesii metaphysicam et responsa(1644). El propio Gassendi (1962) sostuvo que esta obra fue destinada a la lectura pública, a diferencia de la editada a solicitud de Descartes ${ }^{6}$. En Disquisitio las críticas fueron dirigidas a casi cada una de las líneas de las Meditaciones metafísicas y, en este sentido, incluyó el texto de las Quintas objeciones.

Aparentemente, Descartes nunca estuvo -ni con las Objeciones ni con la Disquisitio- muy convencido de tener que afrontar tan seriamente las críticas de Gassendi. En las siguientes líneas podemos revisar el juicio de Descartes relativo a las Quintas objeciones, y en especial se puede hacer una idea del tono en que ellas fueron formuladas:

[...] si bien es cierto que no habéis usado las razones de un filósofo para refutar mis opiniones, cuanto los artificios de un orador para eludirlas.... y pienso que vuestro único propósito ha sido avisarme de los medios que podrían emplear para eludir mis razones aquellas personas cuyo ingenio está tan apegado a los sentidos que solo puede pensar algo imaginándolo, siendo, por tanto, ineptas para la especulación metafísica, y me dais así ocasión, con vuestra advertencia, de salirles al paso. Por ello, no creáis que, al responderos aquí, me dirijo al agudo y sutil filósofo que sé que sois, sino que os hablo como a uno de esos hombres de carne con cuya faz os habéis revestido (DESCARTES, 2005, p.673-674; DESCARTES, 2000; AT VII, p.347).

${ }^{5}$ DESCARTES (2000). Una síntesis de la historia de las Meditaciones la encontramos en la introducción de Michelle y Jean-Marie Beyssade (BEYSSADE; BEYSSADE, 1992, p.1-28).

6 Descartes (2000, AT IX, p.198-199) hace referencia a la Disquisitio en el "Avertissement de l'àutor touchant les cinquièmes objections". 
Descartes fue consciente de los elementos filosóficos que se jugaban en la disputa. Este es uno de los motivos por el cual se puede detectar una profunda ironía en sus respuestas. Incluso, es posible suponer que nos hemos desviado de los elementos significativos de la querella, producto del sarcasmo compartido entre Descartes y Gassendi.

La comprensión actual del estado de la discusión no ha cambiado sustantivamente desde la opinión misma de Descartes. Cuando la polémica es tomada en cuenta la versión cartesiana parece ser, en general, la más replicada transformándose en una suerte de canon interpretativo. De hecho, para esclarecer la recepción de este diálogo tan crítico, sería inoficioso hacer notar las veces en las cuales las observaciones de Gassendi no han sido tomadas en serio y, por ello, es más fructífero centrarnos en las exposiciones en que sí se les ha relevado ${ }^{7}$.

En este sentido, una primera versión de esta polémica tiende a considerar el resultado de las Objeciones como el producto de una incapacidad de Gassendi para alcanzar un nivel de abstracción metafísica. Incluso, el filósofo de Digne habría sido incapaz de inteligir las Meditaciones. Esto querría decir que no entendió su método, ni sus resultados, ni menos las intenciones filosóficas de Descartes. De hecho, como ejemplo de esto podemos remitirnos a dos anotaciones que Vidal Peña realizó en su traducción de las Meditaciones metafísicas con objeciones y respuestas. Estos comentarios son importantes porque su traducción ha sido un referente de divulgación del cartesianismo en Iberoamérica. Por ejemplo, podemos referirnos a la objeción a la primera meditación, donde el pensador de Digne se pregunta:

\footnotetext{
7 Por ejemplo, me parece que Geneviève Rodis-Lewis hace uso de las ideas de Gassendi para darle continuidad a la argumentación cartesiana, entonces, en el caso que Descartes requiera de un objetor, aparece la objeción de Gassendi con la finalidad de reconstruir positivamente el argumento cartesiano (RODIS-LEWIS, 2013, p. 126, 235, 243, 244, 314, 316). Otro estudio cartesiano que podemos mencionar es el desarrollado por Margaret Wilson en su obra Descartes, donde plantea que el valor de las objeciones de Gassendi dedicadas al pasaje de la cera y al pasaje de la res extensa -relativos a que la mente se conoce mejor que el cuerpo- son de una alta pertinencia y llevan al sistema cartesiano a un punto crítico: "aquí hemos llegado a un punto de importancia crucial en el sistema cartesiano. Se dice que la mente se conoce mejor que el cuerpo -pero esto realmente no puede ser porque nuestro conocimiento de la mente satisfaga en un grado superior los mismos patrones mediante los que evaluamos el conocimiento del cuerpo. Parece que hay dos propuestas que Descartes podría extraer para defender la posición -insinuada al final de su réplica a Gassendi- de que los patrones apropiados para una no son los apropiados para el otro [...]" (WILSON, 1990, p.152) Esto puede leerse como una posibilidad para pensar que Descartes no resuelve el problema del todo y que la respuesta de Gassendi es un pertinente intento de ejercicio crítico.
} 
[...] ¿no habría sido más propio de la honestidad filosófica y del amor a la verdad el decir las cosas sencillamente, de buena fe, y tal como son, en vez de recurrir -como podría objetárseos- a todo ese artificio, a la invención de esas ilusiones y la maquinación de esos rodeos? Con todo, pues habéis creído que así estaba bien, nada más tengo que oponer (DESCARTES, 2005, p.532; AT VII p.258).

Inmediatamente al texto anterior, Vidal Peña nos plantea:

[...] esta objeción manifiesta, desde el principio, el desdén o la incomprensión de Gassendi por todo el planteamiento 'crítico' de Descartes; su objeción parece asumir deliberadamente un 'sano sentido común' (en cierto modo, "antifilosófico") desde el cual la propuesta de sutiles dificultades no es más que "palabrería" [...] El 'tono' de Gassendi es, muchas veces (sin perjuicio de ocasionales ingeniosidades) el de una grosería que se complace en sí misma (DESCARTES, 2005, p.532-533).

Y a continuación, Descartes, 2005, p.536) agrega: “[...] la obsesión analítica de Gassendi parece impedirle entender ni de lejos en qué consiste "la duda" cartesiana $[\ldots .]$.

A nuestro juicio, los comentarios de Vidal Peña no clarifican los elementos conceptuales que nos permitan comprender las razones de la posición de Gassendi. Además, podríamos afirmar que es una nota completamente cartesiana si es que recordamos el juicio general de Descartes respecto de las Disquisitio: "todas las objeciones que ese libro contiene, están fundadas en palabras mal entendidas o suposiciones falsas" (DESCARTES, 2005, p.735). De hecho, Descartes (2005) en más de algún punto ni siquiera se molesta por contestar las observaciones de Gassendi, tal como sucede con el caso de la interacción mente-cuerpo, aunque debemos reconocer que, más tarde, discutirá abiertamente acerca de este tema en la correspondencia con Elizabeth de Bohemia ${ }^{8}$. Pensamos que la perspectiva recogida por los comentarios de Vidal Peña condiciona la lectura de las objeciones gassendianas y la óptica de un Gassendi "filosóficamente incompetente", se perpetúa. En síntesis, la posición canónica interpretativa ha dejado a los argumentos de Gassendi

${ }^{8}$ ELISABETH DE BOHEMIA, DESCARTES, R. The Correspondence between Princess Elisabeth of Bohemia and René Descartes, Lisa Shapiro (ed. y trad.), University of Chicago Press, Chicago, 2007. Hoy entendemos que Elisabeth fue una continuadora de las críticas gassendianas al tener a Samuel Sorbière -uno de los discípulos de Gassendi- en calidad de cortesano. En español encontramos la traducción de Elisabeth Goguel: DESCARTES, René. Cartas filosóficas. La plata: Terramar, 2008. 
como rústicos embates materialistas y pobres comprensiones empiristas frente a las ricas sutilezas metafísicas cartesianas.

Una segunda tendencia interpretativa abarca diversos estudios que abordaron la cuestión de las diferencias de los principios y de los métodos que habrían separado de modo radical a ambas filosofías. En este sentido, estos estudios han mostrado una disputa matizada en los aspectos polémicos y enriquecida en los aspectos filosóficos. Si bien no es el lugar para hacer una lista extensiva de estos estudios, quisiéramos mencionar algunas posiciones que a nuestro juicio corresponden a esta segunda tendencia historiográfica.

En esta vía cabe destacar el trabajo de Margaret Osler (OSLER, 1994) quien postuló que las diferencias entre ambas filosofías devinieron como consecuencia de las estructuras teológicas operantes en cada uno de los sistemas filosóficos (Dios como potencia absoluta en Gassendi, y Dios como potencia ordenada en Descartes); Para Thomas Lennon (LENNON, 1993) el objeto central de la crítica de Gassendi es la noción de representación en Descartes y en el despliegue argumentativo de ambos pensadores respecto de esta noción se muestra la imposibilidad de comunión entre sus filosofías y sus consecuencias históricas que dejaron como herencia sus legados respectivos; Rafael Corazón, intentando afirmar de manera general que la crítica de Gassendi diagnostica la imposibilidad de la filosofía cartesiana para reemplazar al tomismo, afirmará:

Toda la crítica de Gassendi está en su concepción de las ideas, pues de aquí se van a seguir consecuencias contrarias a la teoría cartesiana. Para Gassendi toda idea es una construcción de la mente hecha a partir de los datos inmediatos de los sentidos. Según esto el primer punto a destacar es que no puede haber un pensamiento que no lo sea de ninguna idea; la independencia que Descartes cree lograr con la duda universal -independencia respecto de todo contenido objetivo- es imposible (CORAZÓN, 1995, p.100).

Antonia LoLordo revisa en detalle la polémica y sostiene que el trabajo de Gassendi puede comprenderse a la luz de una psicología sistemática de corte epicureana (LOLORDO, 2001). En parte, esta posición profundiza el análisis realizado por Bernard Rochot en Les travaux de Gassendi sur Épicure et sur l'atomisme 1619-1658 (ROCHOT, 1944). Esta exégesis neoepicureana tiene el desafío de explicar cómo los momentos escépticos gassendianos quedan yuxtapuestos a las tesis epicúreas y materialistas. Esta posición necesita considerar que, durante aquellos años de la polémica, Gassendi transformó su 
escepticismo radical inicial en pro de un neo-epicureanismo que terminaría por ser reformulado. Por ejemplo, desde el año1626 tenemos evidencia epistolar de la necesidad de incorporar a su propia filosofía algunos elementos extrínsecos al modelo epicúreo materialista ${ }^{9}$, tal como lo es el finalismo en el sistema natural que formuló en su etapa madura. Con esto queremos decir que debemos pensar al Gassendi de la polémica como un epicúreo, pero que también hay que pensarlo como algo más que un mero epicúreo.

Las interpretaciones anteriores -aquellas que valoran positivamente las objeciones de Gassendi- han mostrado pliegues de los elementos filosóficos subyacentes a la polémica; sin embargo, dado el amplio espectro de las consideraciones críticas de nuestro autor dirigidas contra el pensamiento cartesiano, no ha sido, ni es fácil, determinar elementos comunes y subyacentes a todas ellas.

En este contexto, consideramos que volver a esta polémica del siglo XVII no tan solo es válido, sino que también es necesario porque tenemos un problema que nos interpela: ¿Cómo se articulan el escepticismo y epicureísmo como sustentos de las críticas de Gassendi a las Meditaciones metafísicas? De esta pregunta dependerá dilucidar si las objeciones de Gassendi son una mera comprensión errada de Descartes -tal como una fuerte tradición historiográfica lo ha considerado- o bien tienen sentido y debemos releerlas a partir de interpretaciones más amplias.

\title{
2 El escepticismo gassendiano fRENTE al esCePticismo de las MEDitaCiones METAFÍSICAS
}

La siguiente afirmación extraída de las Objeciones de Gassendi, inicia las críticas contra el método, del siguiente modo:

\begin{abstract}
Así pues, [estas críticas] las propongo, pero solo como algo que no va contra las materias de que tratáis sino contra el método y las razones que usáis para demostrarlas. Pues, en verdad, hago profesión de creer que hay un Dios tres veces grande, y que nuestras almas son inmortales; mi sola dificultad está en comprobar la fuerza y energía del razonamiento que empleáis a fin de probar tales verdades metafísicas, y las demás que con ellas se relacionan (DESCARTES, 2005, p.531; DESCARTES, 2000, AT VII p.257).
\end{abstract}

\footnotetext{
9 Cfr. Petrus Gassendi, Opera Omnia, Stuttgart-Bad Cannstatt: Friedrich Fromman Verlag Günter Holzboog, 1964 p.20aa en adelante usaremos la nomemclatura canónica de GASSENDI, 1964, O.O.VI, 20a; Cfr. también en DUCHESNEAU, 1998, p.97; GASSENDI, 2004, p.33-40.
} 
La observación de Gassendi de ir "contra el método y las razones de que usáis para demostrarlas" no es, entonces, ni anecdótica, ni tangencial. Por el contrario, ella quiere atacar el corazón mismo del modo en que las Meditaciones se han desplegado. Entonces, al menos, ya sabemos algo: Gassendi entiende que para Descartes su filosofía se basa en el método e intentará buscar los límites explicativos de la duda metódica cartesiana. Ahora bien, el modo en que Gassendi llevará a cabo su estrategia es trasladar las cuestiones metafísicas al dominio epistémico, preguntándose si es posible rendir cuenta de lo metafísico a partir del intento de explicar los fundamentos y límites de las capacidades naturales del entendimiento humano.

Este mismo pasaje nos muestra que para el filósofo y sacerdote francés, afirmar la existencia de entes metafísicos no es problemático al nivel de una creencia. Estar convencido de una idea que refiera a entidades metafísicas no es difícil para un neo-epicureano al estilo de Gassendi. Por ejemplo, la idea de "Dios" se puede explicar a través de la acción, de la composición y de la amplificación que lleva acabo el intelecto con el dato básico-sensible proveniente de las imágenes de "hombre viejo venerable" ${ }^{10}$ y en ningún caso ello quiere ser presentado como una irreverencia teológica, ni doctrinal, ni filosófica. Para ambos pensadores es posible tener la idea de Dios, solo que para Gassendi lo problemático es intentar la demostración racional de la existencia de una res divina al modo cartesiano. Un procedimiento de tal factura evita el trato con los datos de los sentidos, con la referencia a la experiencia sensible y, por supuesto, con los límites de lo que para Gassendi implica todo conocimiento efectivo.

La raíz misma del conocimiento y los límites propios de la experiencia tratada por el entendimiento son parte de la estructura básica con la cual obtenemos la información proveniente del mundo y es a partir de este supuesto que Gassendi entiende los límites de todo tipo de método. La facultad de conocimiento puede hacer elaboraciones precisas de los datos ofrecidos por las sensaciones, pero ella en tanto aparato básico de la estructura gnoseológica, no puede ir más allá de aquello que la experiencia misma nos puede ofrecer. Una experiencia metódica basada solo en la experiencia del pensar de la res cogitans, sería para Gassendi una experiencia ficticia, un ejercicio mental que supone ser -él mismo- una cosa sin historia y sin cuerpo.

${ }^{10}$ GASSENDI 1964, O.O. I, 92b. Cabe señalar que durante los años de la polémica, Gassendi hereda los trazos fundamentales del empirismo epicureano, el cual deviene más tarde en una formulación propia destacada en el Syntagma philosophicum (O.O.I.92b-99b) texto en el que se muestra el canon epistemológico de Gassendi, fuertemente epicúreo. 
En las Objeciones a la primera meditación, Gassendi interpreta que Descartes ha fingido usar el escepticismo para construir un sistema metafísico inamovible, dado de una vez y para siempre. Siguiendo la enseńanza de Sexto Empírico (2009) ${ }^{11}$, el filósofo de Digne considera que todo aquel que acepte el acceso a la verdad misma de las cosas debe ser considerado un dogmático. De esta manera, para Gassendi los dogmáticos -como los escolásticos y en este caso Descartes- tienen como supuesto fundamental que toda filosofía posee un criterio absoluto de qué es y qué no es verdadero a priori. Según Gassendi, en este caso el escepticismo metodológico cartesiano es solo un pretexto para afirmar creencias concebidas de antemano y no una auténtica investigación filosófica.

Más bien, la actitud escéptica gassendiana fue una posición filosófica que se caracterizó por negar el acceso intelectivo a la esencia, a la sustancia y a la verdad metafísica. Sin embargo, habría que recordar que en Gassendi el escepticismo se manifestó en diversos grados. El periodo entre los años 1621 al 1624 se afirmó en un escepticismo radical muy al estilo de Sexto Empírico, lo cual fue patente en su obra contra los Aristotélicos (1624) ${ }^{12}$; luego, según Popkin (2003), transitó hasta un escepticismo mitigado en su filosofía madura del Syntagma philosophicum (1658). En esta última obra, si bien la verdad de la cosa en sí no se conoce, podemos tener un conocimiento perfectible, probable e hipotético de los fenómenos observados. La obtención de este conocimiento se basa en los datos obtenidos de los sentidos y en la articulación coherente que el intelecto puede realizar en relación a los procesos del conocimiento y a los fenómenos de la cosa estudiada. De allí que el único criterio posible es aquel basado en lo sensible y en el trato con aquellos datos (GASSENDI, 1964, O.O.I.92b-99b). Pues bien, quisiéramos resaltar que esta última tesis es la que está emergiendo en la Disquisitio.

Toda la década anterior a las Quintas objeciones, vale decir, durante la década del treinta, el epicureísmo y la ciencia nueva hicieron mella en las creencias escépticas radicales sostenidas por Gassendi en su juventud. Y en ese sentido, Gassendi cuando enfrenta a las Meditaciones lo hace teniendo la idea de que un posible criterio de verdad deviene de los sentidos ${ }^{13}$, pero ello

\footnotetext{
${ }^{11}$ Debemos hacer notar que la influencia del escepticismo de Sexto Empírico, los principios pirronianos y de Charron fueron constituyentes del espíritu filosófico del joven Gassendi, tal como el mismo lo ha dejado entrever en el prefacio a su obra contra los Aristotélicos. PIERRE GASSENDI,1959, p.6-7.

${ }^{12}$ GASSENDI, 1956.

${ }^{13}$ Rochot (1944, p.31-42) ha destacado que desde el año 1629 el deseo de Gassendi es llevar a cabo una traducción más fiel del libro X de Diógenes Laercio De Vita, morivus, placitisqve epicuri, cvm nova
} 
no aparece en las objeciones en el modo afirmativo de una tesis propuesta y definitiva, sino que es usada como una alternativa que intenta contrapesar el espíritu de la certeza cartesiana. En este sentido, el escepticismo sigue operando de manera crítica en las objeciones contra el pensamiento cartesiano.

En este contexto, debemos comentar que si bien Gassendi acusa a Descartes de usar un método artificial, no es menos cierto que el mismo Gassendi utiliza el método escéptico de manera operativa: cada vez que él pueda ofrecer una alternativa a la verdad cartesiana expuesta en las Meditaciones, yuxtapondrá una exégesis que pueda ser más económica y que esté de acuerdo con los criterios de los sentidos y las facultades que los tratan. El fin de esta estrategia es la suspensión del juicio. Vale decir, Gassendi necesita frenar la afirmación de Descartes relativa a la captación intuitiva de la verdad de la cosa, y para ello Gassendi yuxtapone las posibilidades interpretativas del epicureísmo. Parece que el aforismo "Pues el pirrónico a ninguna de las cosas que no se manifiestan da su asentimiento" (SEXTO EMPÍRICO, 2009, p.55) tiene en Gassendi el siguiente uso: mostrar que la manifestación de la verdad de la res no se ha alcanzado y que existen otras opciones.

Pero cabe preguntarnos si Gassendi establece un sistema filosófico alternativo al cartesiano al momento de ofrecer otras opciones interpretativas tanto en las Objeciones como en la Disquisitio. Ante esta interrogante deberíamos responder negativamente, pues el escepticismo operativo de Gassendi pretende -tal como hemos afirmado anteriormente- oscurecer la claridad y distinción de la verdad cartesiana. Si esto último se logra, entonces, la tarea de la crítica está completa y el rol del epicureísmo es aportar sombras ante la aparente claridad ganada en las afirmaciones cartesianas.

Gassendi en la Disquisitio se esforzará por mostrar la artificialidad del método cartesiano. Un ejemplo de esta artificialidad sería la incapacidad de liberar a la mente de todos los prejuicios, al modo pretendido por Descartes. Gassendi (1962, p.36-37) se referirá al respecto del siguiente modo:

Usted supone primero que la mente puede ser liberada de todo prejuicio: pero la cosa parece imposible. De partida porque la memoria, es como el tesoro de los juicios que hemos formulado antes y que puestos en ella, no pueden ser borrados a nuestra voluntad [...]

interpretatione, et notis (GASSENDI, 1964, O.O.V). Posteriormente, estos estudios posibilitaron un manuscrito fuertemente epicureano intitulado La Logique de Carpentras (GASSENDI, 2012), texto que fue una de las bases filosóficas importantes para la canónica publicada en el Syntagma philosohicum (GASSENDI, 1964, O.O.I). 
El sujeto de conocimiento Gassendiano debe incluir la estructura de la memoria, estructura fisiológica e histórica, porque el alma material solo recibe los fenómenos que pasan en un tiempo y en un espacio. La estructura de la experiencia y la sensibilidad arraigada en el sujeto empírico es una condición que ningún método puede evadir. Aquí la herencia de la prolepsis epicúrea y de su relación con la función de la memoria, será fundamental (ALBERTI, 1988) y esta influencia quedará explicitada en el manuscrito de Carpentras de 1636 donde la sensación, la prenoción y la afección serán los criterios de verdad posible (GASSENDI, 2012, p. 201; p. 294 y ss.; DIOGENES LAERCIO, 2013, p.573). Parafraseando a Gassendi, debemos considerar que todo acto de investigación, búsqueda, comprensión, opinión, refutación y exposición quedará supeditado a la praenotio (GASSENDI, 2012, p.295). La memoria guardará las experiencias de las cosas y ella posibilitará que la prolepsis o praenotio sea posible. En el fondo, Gassendi interpelaría a cualquier modelo explicativo que desconozca el lugar fundante de la praenotio para el conocimiento $^{14}$.

Lo anterior hace comprensible que Gassendi hubiese abandonado la doctrina del escepticismo radical tan importante en su formación filosófica (GASSENDI, 1959, p.6-7). Esto en pro de una posición menos categórica donde se postula un probabilismo epistémico que es coherente con los nuevos descubrimientos de la ciencia nueva sustentados desde una mirada epicúrea. Sin embargo, en tanto que nuestro aparato cognoscitivo es de una naturaleza limitada o modesta la verdad misma de las cosas seguirá estando oculta.

En cambio, para el modelo que expresa Descartes en las Meditaciones, la certeza científica se basa en el carácter autoevidente de las verdades metafísicas. Según Rodis-Lewis (2013, p. 8) "El orden analítico de las razones [cartesianas] "muestra la vía verdadera por la cual una cosa ha sido metódicamente inventada" El orden analítico de las razones [cartesianas] "muestra la vía verdadera por la cual una cosa ha sido metódicamente inventada". Para Descartes este apriorismo es justamente el lugar donde reside la fuerza de su sistema, mientras que en las Objeciones y en la Disquisitio el desafío de Gassendi, según Bloch (1971, p.121), consistió en demostrar la vacuidad de la pretensión cartesiana:

[Gassendi] observa en Descartes la tentativa de construir una ciencia deductiva, una física, cuya base es la metafísica; a lo que presenta una crítica empirista, nominalista, y antropológica. Así, una vez más, no es

\footnotetext{
${ }^{14}$ AOIZ, Javier, 2012. El artículo de Aoiz es un clarificador esbozo relativo a los criterios de evidencia en Sexto Empírico y Epicuro.
} 
la metafísica sino la metafísica con pretensión de ciencia lo que Gassendi considera un error; por lo que la intención de Gassendi no es oponer un materialismo sistemático a la metafísica sistemática de Descartes si no develar lo vacuo de los presupuestos filosóficos de esta metafísica.

Según Gassendi, los supuestos de la meditación cartesiana -tal como el que podamos eliminar todos los prejuicios del espíritu- operarían al modo de certezas y autoevidencia. Nuevamente es necesario remarcar en esta dimensión, que la pretensión de Gassendi es negativa pues intentará llevar el argumento a un terreno oscuro o difuso. Y, si esto se cumple, entonces, la promesa de claridad y distinción del cartesianismo se nos alejaría. Para nuestro autor, el proyecto cartesiano se otorga a sí mismo una utopía metafísica, un proyecto de fundamentación de la ciencia basada en la ausencia de evidencia real.

A partir de lo anterior, podemos volver a la primera interpretación que sostiene que Gassendi no comprendió la metafísica cartesiana y podemos plantear que las objeciones de Gassendi se sitúan justamente en el plano de las exigencias metodológicas. Gassendi negará los supuestos cartesianos porque eligiendo el mejor método posible, éste no puede ir más allá de lo que nuestra facultad de conocimiento puede ofrecernos, por lo tanto, el método debe ser coherente con la fuente y los límites gnoseológicos propios. Entonces, según nuestro filósofo, Descartes ha rebasado los límites propios de la naturaleza humana al fundamentar el alcance de la meditación en un sujeto imposible de concebir.

Cabe preguntarse por el aspecto positivo del ataque gassendiano y ello nos obliga a señalar que la doctrina postulada por Gassendi no saldrá a la luz sino hasta el Syntagma Philosophicum (1658) obra postmortem donde se fundirán los conceptos epicúreos con los principios de causalidad eficiente y final. El método hará posible el conocimiento desde el dato básico de los sentidos con los cuales el entendimiento logrará elaborar ideas más complejas y generales, con las que se permitirá mantener el nexo explicativo con la experiencia en un marco atomista y de hipótesis explicativas probabilísticas relativas al conocimiento del mundo (FISHER, 2005). 


\section{LOS ELEMENTOS CRÍTICOS AL SISTEMA CARTESIANO: EL EXCESO DEL ESPÍRITU Y}

\section{LA SUSTANCIA}

Reconozcamos que Vidal Peña tiene razón al plantear que Gassendi dividiendo paso a paso el discurso cartesiano, tiene un espíritu analítico. Por nuestra parte quisiéramos ir más allá de la forma y concentrarnos en el fondo de la crítica. En otras palabras, intentaremos dar cuenta de cómo Gassendi aborda la metafísica cartesiana. En este sentido, el modo en que Descartes expone su noción de res aparece como apropiada para mostrar de qué manera la crítica gassendiana enfrentó este problema.

Por ejemplo, las objeciones que Gassendi realiza a la noción de res cogitans se desarrollan en referencia a cuáles son las funciones del espíritu y cuáles son sus diferencias con relación al "alma de los animales". Recordemos que la noción de anima brutorum ${ }^{15}$, Esprit des animaux, Aime de bêtes fue un tópico de la filosofía moderna y que la filosofía gassendiana rescató desde los modelos corpuscularistas de comprensión del ser humano. Si bien el alma de los animales es sumamente sutil e imperceptible, ella es de suyo, material. Ella estaría compuesta por los corpúsculos más excelsos y finos de la materia, una suerte de flor de la materia (flos materiae).

El alma de los animales tiene como función alojar a la capacidad de imaginación y tiene por constitución solo lo natural, inmanente y corpuscular (DUCHESNEAU, 1998, p.98-106). Ella sería el alma que compartiríamos con otros animales. Para Gassendi esta hipótesis explicativa tiene el beneficio de que nos mantiene al interior de una explicación de lo natural en lo natural, lo que se constituye en un requisito de toda investigación epistémica. Además, postular esta suerte de "alma ígnea" nos facilitaría la comprensión de las relaciones entre las funciones cognitivas-imaginativas y las corpóreo-sensibles: que el cuerpo sienta y que la mente imagine es producto de la acción del "Esprit des animaux", entidad que tiene como propiedad comprender la actividad de los corpúsculos involucrados en la relación de nuestro aparato sensitivo con las cosas sensibles.

Para Gassendi las cosas naturales son siempre en algún sentido sensibles: ya sea aprehender una idea compleja a partir de ideas simples o aprender ideas simples en relación con las cosas que impresionan los sentidos. Allí radica la

${ }^{15}$ Cfr. GASSENDI O.O. II, 251a. En el capítulo "Quidsit anima brutorum” del Syntagma philosophicum, Gassendi postula la siguiente definición: "El alma me parece, entonces, ser una cierta pequeña flama, una especie de fuego muy tenue, que tanto tiempo que ella vive, vale decir, que permanece encendida, asi tanto tiempo vive el animal: cuando ella no vive más, entonces se apaga, el animal muere." 
fuente de la idea, de la notio, en definitiva, de la imagen representada en el intelecto y que siempre provendrá adventiciamente desde la cosa. Esto no significa que no existan conceptos que de suyo sean inmateriales, sino que la fuente es siempre una cuestión natural y particular. El ejemplo de esto es el caso del concepto "humano": solo conocemos individuos que luego se pueden clasificar intelectual y lógicamente en una misma clase.

En las Meditaciones la idea de alma de los animales fue planteada y luego criticada por Descartes (2005, p.145; AT. VII, p.26) en los siguientes términos:

[...] pero no me paraba a pensar en qué era esa alma, o bien, si lo hacía, imaginaba que era algo extremadamente raro y sutil, como un viento, una llama o un delicado éter, difundido por mis otras partes más groseras [...]

Pero esta concepción material de "Esprit des animaux" es confusa para Descartes y se la debe dejar de lado en pro de un espíritu libre de las espurias consecuencias de la materia porque, para él, solo en lo más desprovisto del cuerpo es que se hace justicia al atributo principal de la res cogitans.

En oposición a lo anterior, Gassendi sostiene que el "alma de las bestias" es un dispositivo coherente epistémica y ontológicamente. Epistémicamente sería coherente puesto que relaciona fenómenos adventicios provenientes de las cosas con funciones naturales de la facultad de conocimiento; luego, ontológicamente sería coherente puesto que se da una relación corpuscular entre un aparato cognoscitivo constituido de los corpúsculos más excelsos de la materia con elementos que son atómicos, al modo de los simulacros epicúreos. Esta suerte de homogeneidad ontológica y epistemológica ofrece posibilidades explicativas para Gassendi que le hacen preguntarse si realmente es necesario referirnos a un espíritu cartesiano completamente incorpóreo.

En el fondo, podríamos referirnos a la crítica de Gassendi en los siguientes términos: parece ser que metodológicamente es innecesario dar cuenta de fenómenos naturales como el conocimiento de una "cosa", con elementos que serían en algún respecto foráneos al mundo natural. Entonces, buscando la explicación más simple deberíamos poder dar cuenta de la máxima cantidad de fenómenos y todo ello sin tener que recurrir al dualismo ontológico.

Una segunda crítica que podemos mencionar es la que opera constantemente en el fondo de la estrategia gassendista. Ésta objeta que la filosofía cartesiana no da cuenta de la noción misma de sustancia. Esto quiere decir que, para nuestro pensador, se debería demostrar qué es y cómo opera la 
sustancia misma. En el caso de la res cogitans, es la res la que debe ser explicada y no meramente su atributo principal. Por cierto, lo mismo será replicado para los conceptos cartesianos de res extensa y de res divina.

El clásico pasaje cartesiano de la cera (Cf. DESCARTES, 2005, p.151; AT VII, p.24) parece ser la defensa de la hipótesis de la eliminación de lo sensible como condición previa para acceder a lo inteligible de la realidad del mundo. Según Descartes, eliminar la sensibilidad -y con ello el rol que cumpliría la imaginación en su captación- es una condición necesaria para acceder a la naturaleza íntima de la realidad corporal que tiene a la extensión como principal atributo. Este acceso cartesiano directo desde la intuición intelectual a la naturaleza geométrica de la res extensa contrasta con la naturaleza compleja de la sensación y de la imaginación. Tal y como lo señala Rodis-Lewis (2013, p.329):

De la segunda Meditación, el análisis de la cera ha despejado la diferencia entre el carácter limitado de las sensaciones confusas y variables, así como las figuras que yo imagino en ella y la infinitud de cambios de la que la concibo capaz $[\ldots]$

En oposición a lo anterior, Gassendi en el texto de las Objeciones se referirá al pasaje de la cera de la siguiente manera:

Todo el mundo está de acuerdo en que puede abstraerse el concepto de cera, o de substancia, del de sus accidentes; pero ¿podéis decir por ello que concebís con distinción la substancia o naturaleza de la cera? Es muy cierto que, además del color, la figura, la capacidad de fundirse, etc... concebimos que hay alguna cosa que es sujeto de los accidentes y los cambios observados; pero no sabemos qué es o qué puede ser dicha cosa, pues siempre permanece oculta y juzgamos solo como por conjetura que debe de haber algún sujeto que sirva como de sostén o cimiento a todas las variaciones de que la cera es capaz. (DESCARTES, 2005, p.554; AT VII p.271)

En este mismo orden, el planteamiento gassendista exige metódicamente que la sustancia sea expuesta a la luz de la totalidad de sus notas sensibles o empíricas. Ahora bien, Gassendi acepta que nuestro entendimiento sea capaz de construir categorías conceptuales para comprender el mundo, pero es consciente de que el paso de nuestros conceptos a la realidad no es inmediato.

Si no queremos usar artificiosamente nuestros métodos de investigación, lo que deberíamos acatar es que el orden natural sea comprendido, pero jamás 
ir más allá de la evidencia sensible con la cual la mente humana comprende el mundo. Vale decir que por la naturaleza limitada del entendimiento las evidencias obtenidas nunca serán las suficientes para conocer a la verdad misma. En la Disquisitio, Gassendi (1962, p. 186-189) expresa nuevamente su concepción de la siguiente forma:

[...] conocer un atributo, o una propiedad, o un conjunto de propiedades, no es por tanto, conocer la substancia misma o la naturaleza. Todo lo que podemos saber es que, si tales o cuales propiedades se relacionan con una substancia u otra naturaleza, esto nos aparece por la observación y nos resulta evidente por la experiencia. Uno no penetra en la substancia o en la naturaleza interior.

Pero esto mismo ha sido tratado en las Meditaciones intentando dar cuenta de la naturaleza de las ideas como preámbulo a la demostración de la existencia de Dios por la vía de los efectos. Descartes (2005, p.168-169; AT VII p.40) afirmó:

En efecto, las que me representan substancias son sin duda algo más, y contienen (por así decirlo) más realidad objetiva, es decir, participan, por representación de más grados de ser o perfección que aquellas que me representan solo modos o accidentes.

Y, haciendo dicha distinción, preparará el camino para afirmar de qué modo en la idea de una sustancia infinita hay más realidad objetiva que en la idea de una sustancia finita. Gassendi, en las Objeciones, atendiendo a esto, sostuvo:

Y si, en vez de la persona, solo habéis visto la máscara que ocultaba su rostro y los vestidos que le cubrían todo el cuerpo, debe decirse que en verdad que no tenéis idea de ese hombre, o, si la tenéis, que es imperfecta y confusa en extremo.

Infiero de ello que puede tenerse una idea distinta y clara de los accidentes, pero que solo puede tenerse una idea confusa de la substancia bajo ellos latente. De manera que cuando decís que hay más realidad objetiva en la idea de substancia que en la de los accidentes, debe negarse, en primer lugar, que sea posible tener una verdadera idea de la substancia, y, por tanto, que pueda poseer su realidad objetiva. (DESCARTES, 2005, p.406407; AT IX p.144) ${ }^{16}$

\footnotetext{
${ }^{16}$ Cabe señalar que esta misma objeción es también mencionada por Hobbes en las Terceras Objeciones, específicamente la objeción novena del inglés (DESCARTES, 2005, p.406-407; AT IX p.144).
} 
Pese a que la argumentación cartesiana intentará separar al espíritu -en tanto que proceso intelectivo- de la imaginación -como proceso sensible e imaginativo-, el ejercicio argumentativo de Gassendi pone de manifiesto que la estructura sensible para el conocimiento de la sustancia es una condición que no puede evitarse en pro de un acceso intelectivo puro. En este aspecto es interesante remitirnos al comentario que Vidal Peña ha realizado en la nota no32:

Gassendi pisa aquí terreno sólido, e históricamente muy importante el de la progresiva crítica del empirismo a la idea de substancia. Una cosa es, en efecto, hablar de la realidad de las ideas (como 'esencias' o 'estructuras') y otra, hablar de la realidad de la 'substancia' tradicional término filosófico que parece mentar una entidad misteriosa e inaprehensible. Los empiristas criticarán la substancia fundándose en que todo lo que sabemos de ella lo sabemos por los accidentes o modos y, eso supuesto, ¿por qué postular que, además, existe una fantasmal entidad bajo ellos? Por otra parte, Descartes mismo ha reconocido que nuestro acceso a la noción de substancia no es inmediato, con lo que la objeción de Gassendi tiene pleno sentido. (DESCARTES, 2005, p.577)

De todas formas, Descartes (2005, p. 697; AT VII 364) respondió del siguiente modo a la objeción de Gassendi:

Más cuando decís que la idea de substancia no tiene más realidad que la que toma de las ideas de los accidentes, con arreglo a las cuales es concebida, dejáis ver claramente que no poseéis idea alguna de la substancia concebida con distinción, porque la substancia nunca puede ser concebida con arreglo a los accidentes, ni tomar en cuenta de ellos su realidad: muy al contrario, los filósofos cuando conciben a los accidentes como reales, los conciben como substancias, pues no puede atribuírseles ninguna realidad (es decir, una entidad que sea algo más que modal) que no haya sido tomada de la idea de substancia.

En estos pasajes podemos ver dos niveles de discusión. En un primer nivel, Descartes prefirió responder evadiendo el fondo epistémico en el cual la objeción le fue formulada y reafirmando la posibilidad de acceso a la sustancia; mientras que, en un segundo nivel, Gassendi interpreta el fenómeno desplazando las cuestiones metafísicas -e incluso doctrinales de la definición de sustancia- hacia cuáles son las capacidades y los límites que tiene el entendimiento. Vale decir, la experiencia misma y los límites de nuestra relación con ella son la evidencia que todo método necesita reconocer. 
Para Gassendi (1959) el plano lógico cartesiano estaría lleno de invenciones formales que son vacías, en tanto en cuanto se observa una falta profunda del momento constitutivo de lo sensible. Entonces, la contra-objeción de Descartes de que "[...] los filósofos cuando conciben a los accidentes como reales, los conciben como sustancias, pues no puede atribuírseles ninguna realidad [...]" (GASSENDI, 1959, p. 36), está pensada en el mero ámbito abstracto y no en el dominio fenoménico-sensible en el que Gassendi deseó circunscribir este problema.

Olivier Bloch (1971, p.121) acentuando la crítica de Gassendi contra Descartes nos plantea que:

Es verdad que, como dijo Descartes, el espíritu humano no puede conocer de la substancia más que sus atributos, pero no tenemos el derecho, por tanto, a decir que la substancia en su realidad no es nada más que los atributos que conocemos: ya sea se trate del pensamiento, de la cera, del imán, la naturaleza íntima de la substancia es radicalmente diferente de las propiedades que captamos por observación o por experiencia; conocer esto no es conocer la naturaleza de la substancia ella misma.

Bloch considera que Gassendi ha detectado que en la filosofía cartesiana hay un problema metodológico que involucra el modo en que a partir de la "conciencia del yo" se transitó hacia el conocimiento de la sustancia. Bloch (1971, p.122) continúa de la siguiente forma:

[...] la crítica al método subjetivo rápidamente conduce a una serie de argumentos que resaltan la imposibilidad de pasar de la conciencia existencial, tal como lo es la conciencia de sí, a la conciencia de una esencia, del conocimiento existencial y exterior de lo real a la intuición de una substancia.

La posición de Bloch se articula coherentemente con lo que hemos sostenido. Si llevamos la discusión a un nivel metodológico, Gassendi apuesta por la necesidad de la simplicidad explicativa y por ello la negación de entidades innecesarias tal como sería el alma cartesiana; por otro lado, la controversia en relación al problema del conocimiento de la sustancia, nos ofrece la posibilidad de entender el modo empirista y los supuestos escépticos que operan en las Objeciones de Gassendi. 


\section{REFLEXIONES FINALES}

A lo largo de este trabajo hemos revisado brevemente la historiografía contemporánea que se ajusta al canon tradicional, la que sostiene que Gassendi no comprendió la filosofía de Descartes y hemos intentado dar razones por las que esta versión necesita ser revisada. Por otra parte, consideramos que las interpretaciones contemporáneas que valoran positivamente al pensamiento de Gassendi han sostenido que la crítica gassendiana devino fuertemente condicionada por las inclinaciones hacia el proyecto epicureísta y materialista, pero sostenemos que en ningún caso la polémica contra Descartes sería la exposición positiva de la totalidad de dichas tesis.

De hecho, cumpliendo con el objetivo crítico que se trazó Gassendi no se observa en la Disquisitio la exposición de un sistema alternativo al cartesiano. La obra contiene notas escépticas, contenidos empiristas y tesis epicúreas, todas ellas yuxtapuestas en la proyección de desmantelar el modo en que la fortaleza cartesiana se construyó. Es cierto que el texto como bien han destacado otros autores, contiene aproximaciones nominalistas $\mathrm{BLOCH}$, 1971, p. 121) ${ }^{17}$ pero estas son una actitud complementaria que permite desplegar con más efectividad las armas del escepticismo y del epicureísmo.

Ni en las Objeciones, ni en la Disquisitio, Gassendi alcanzó a promover una alternativa sistemática a la opción cartesiana. Más bien los procedimientos de nuestro filósofo estaban en pleno proceso para constituirse en una filosofía alternativa. Todos los niveles y ejemplos yuxtapuestos nos permiten comprender la actitud crítica de Gassendi hacia Descartes. Si las críticas fueron medianamente bien llevadas, ello implica que Gassendi estaba comprendiendo el proyecto cartesiano. En parte, el mismo Vidal Peńa haciendo un acto de justicia interpretativa concede que Gassendi al menos "hace pie firme" con la crítica contra el conocimiento de la sustancia.

Nos parece que Gassendi ha intentado mostrar que, en las Meditaciones metafísicas, su autor no se hizo cargo de explicar radicalmente el modo en que se fundan sus principios y Gassendi intenta por sus medios exponer las tesis cartesianas y dejarlas, en el mejor de los casos, como poco probables. En buena medida, esto implicaría desmitificarlas en tanto que verdades demostradas y, más aún, como intuiciones directas del espíritu.

Si las críticas de Gassendi tienen sentido, entonces, las complicaciones para el modelo cartesiano son difíciles: si no hay verdades fundamentales o

\footnotetext{
${ }^{17}$ De hecho, para Bloch el nominalismo sería "la punta de lanza del ataque".
} 
sustancias que se expliquen con referencia a los criterios de la experiencia sensible y fenoménica, entonces sería un sistema vacío. Más bien, para Gassendi el ejercicio cartesiano sería una suerte de un a priori metafísico sobre los cuales la ciencia no puede, ni debe, fundarse.

Según Sorbiere ${ }^{18}$, Descartes y Gassendi limaron asperezas y se declararon mutua admiración. Sin embargo, la polémica ha seguido extendida en cualquier disputa donde se reclame cualquier exceso de trascendentalismo, apriorismo o modos en que la "carne" en tanto que contenido experiencial sea obviada del fenómeno a comprender.

En parte, todos estos entrecruces de motivos y yuxtaposiciones que alejaron el pensamiento de los filósofos hacen de las quintas objeciones y de la Disquisitio, una pieza clave para entender la comprensión que se jugaba en pleno siglo XVII en torno al ser humano y sus capacidades, al conocimiento de la naturaleza y la estructura epistémica de la ciencia. Los embates de Gassendi son reflejo de un filósofo preocupado por discutir aspectos cruciales que luchaban por reformularse ante el escenario de la naciente ciencia nueva.

Relevando el carácter crítico de las objeciones, Lennon (1993, p.108) ha planteado:

Las Objeciones de Gassendi pueden ser bien vistas como [las] únicas. Entre otros objetores, Arnauld realmente pregunta por clarificaciones, y los teólogos escolásticos comparten importantes presuposiciones metafísicas con Descartes. Hobbes quien no se involucra con Descartes más que yuxtaponiendo, con sus propios puntos de vistas a aquellos de Descartes, [y] con Descartes respondiendo del mismo modo. En el caso de Gassendi, sin embargo, encontramos una elaborada y sistemática confrontación metafísica.

La idea expresada por Lennon resulta provocadora ante la historiografía contemporánea y al menos nos llama a una relectura de la posición gassendiana frente a Descartes. Nuestro trabajo, en parte, ha querido mostrar que al menos dos observaciones gassendianas -contra el método y contra la sustancia- tienen sentido y que aquellas críticas son una muestra de que Gassendi no quiere aceptar los postulados cartesianos porque a estos les falta un piso irrecusable

\footnotetext{
${ }^{18}$ Samuel Sorbière escribe el prefacio que aparece en el Opera omnia de Gassendi (O.O. I) y recientemente contamos con una traducción en Taussig, S., Turner, A., Mémoire de Gassendi, Vies et célébrations écrites avant 1700, Brepols, Turnhout (2008, p. 448-451).
} 
que se debe considerar: las limitaciones de las facultades cognitivas que posibilitan la experiencia sensible.

HERRERA-BALBOA, S. Gassendi's objections to descartes's Meditations on first philosophy in their philosophical context. Trans/form/ação, Marília, v. 43, n. 3, p. 339-360, Jul./Set., 2020.

\begin{abstract}
The quarrel between Pierre Gassendi and René Descartes has been treated generally from the Cartesian perspective, but our work focuses on Gassendi's philosophy instead. In this sense, we want to find a more comprehensive way to integrate the internal logic that articulated Gassendi's objections. We will try to show the contemporary reception and the logic of his philosophical assumptions or the strategy that operates under these objections. Besides, we will explain the contemporary reception of this polemic and the main critical issues adopted by Gassendi about "method" and "substance". To accomplish these tasks, we will study Gassendi's objections to the Meditations on first philosophy, as well as the Disquisitio metaphysica seu dubitationes et instantiae adversus Renati Cartesii metaphysicam et responsa, a work published by Gassendi in 1644 .
\end{abstract}

Keywords: Gassendi. Objections. Descartes. Skepticisms. Early modern philosophy.

\title{
REFERENCIAS
}

AOIZ, Javier. La evidencia en la filosofía antigua. Azafea, Revista de Filosofía, Universidad Salamanca, n.14, p.165-179, 2012,

BEYSSADE, Michelle et Jean-Marie. Descartes, Méditations métaphysiques. París: Flammarion, 1992.

BLOCH, Olivier. La philosophie de Gassendi. Nominalisme, Matérialisme et Métaphysique. La Haya: Martinus Nijhoff, 1971.

DE BOHEMIA, Elisabeth. René Descartes, The Correspondence between Princess Elisabeth of Bohemia and René Descartes. Chicago: University of Chicago Press, 2007. CORAZÓN, Rafael. Hombre y Verdad en Descartes. Navarra: Cuadernos de Anuario Filosófico, 1995.

DESCARTES, René. Cartas filosóficas. La Plata: Terramar, 2008.

DESCARTES, René. Meditaciones Metafísicas. Oviedo: KrK, 2005.

DESCARTES, René. CEuvres Completes. París: J.Vrin, 2000.

DESCARTES, René. CEuvres philosophiques. París: Classiques Garnier, 1988. 
DUCHESNEAU, François. Les modèles du vivant de Descartes à Leibniz. París: J.Vrin, 1998.

GASSENDI, Pierre. Disquisitio metaphysica seu dubitationes et instantiae adversus Renati Cartesii metaphysicam et responsa(1644)/ Recherches métaphysiques, ou doutes et instances contre la métaphysique de $\mathrm{R}$. Descartes et ses réponses. París: J.Vrin, 1962.

GASSENDI, Pierre. Exercitationes Paradoxicae Adversus Aristoteleos (1624)/ Dissertations en forme de paradoxes contre les Aristotéliciens. París: J.Vrin,1959.

GASSENDI, Pierre. La logique de carpentras. Turnhout: Brepols, 2004.

GASSENDI, Pierre. Lettres Latines. Turnhout: Brepols, 2004.

GASSENDI Petrus. Opera Omnia. VI volúmenes, Stuttgart-Bad Cannstatt: Friedrich Fromman Verlag Günter Holzboog, 1964.

FISHER, Saul. Gassendi's philosophy and science. Atomism for empiricist. Leiden: Brill, 2005.

LAERCIO, Diógenes. Vidas y opiniones de los filósofos ilustres. Madrid: Alianza, 2013.

LENNON Thomas. The battle of de gods and giants. The legacy of Descartes and Gassendi (1655-1715). Princeton: Princeton University Press, 1993.

LOLORDO, Antonia. Flesh v/s mind, a study of the debate between Descartes and Gassendi. Tesis (Doctorado en Filosofía) - The State University of New Jersey, New Jersey, 2001.

LOLORDO, Antonia. Pierre Gassendi and the birth of early modern philosophy. Cambridge: Cambridge University Press, 2007.

ROCHOT, Bernard. Les travaux de Gassendi sur Épicure et sur l'atomisme. 16191658. París: J.Vrin, 1944.

RODIS-LEWIS, Geneviève. L'oeuvre de Descartes. Paris: J.Vrin, 2013.

TAUSSIG, Sylvie., TURNER, Anthony. Mémoire de Gassendi, Vies et célébrations écrites avant 1700. Turnhout: Brepols, 2008.

OSLER, Margaret. Divine will and the mechanical philosophy. Cambridge: Cambridge University Press, 1994.

POPKIN, Richard. The history of scepticism: from savonarola to bayle. Oxford: Oxford University Press, 2003.

WILSON, Margaret. Descartes. Ciudad de México: UNAM, 1990.

Recebido: 19/11/2019

Aceito: $17 / 02 / 2020$ 